ISSN 0103-5150

Fisioter. Mov., Curitiba, v. 29, n. 1, p. 87-94, Jan./Mar. 2016

Licenciado sob uma Licença Creative Commons

DOI: http://dx.doi.org.10.1590/0103-5150.029.001.A009

\title{
Correlation between balance, speed, and walking ability in individuals with chronic hemiparesis ${ }^{1}$
}

\section{Correlação entre equilíbrio, velocidade e capacidade de deambular em indivíduos com hemiparesia}

\section{Heloisa Maria Jácome de Sousa Britto ${ }^{[a]}$, Luciana de Andrade Mendes ${ }^{[a]}$, Cínthia de Carvalho Moreno ${ }^{[b]}$, Emília Márcia Gomes de Souza e Silva ${ }^{[a]}$, Ana Raquel Rodrigues Lindquist ${ }^{[\mathrm{a}] *}$}

[a] Universidade Federal do Rio Grande do Norte - UFRN, Natal, Brazil

[b] Faculdade Natalense de Ensino e Cultura - FANEC, Natal, Brazil

\section{Abstract}

Alterations in balance and gait are frequently present in patients with hemiparesis. This study aimed at determining whether there is a correlation between static and functional balance, gait speed and walking capacity. To that end, 17 individuals with chronic hemiparesis of both sexes ( $58.8 \%$ men and 42.25 women), mean age of $56.3 \pm 9.73$ years, took part in the study. Static balance was assessed by computerized baropodometry, under two different sensory conditions: eyes open (EO) and eyes closed (EC). Functional balance was evaluated by Berg Balance Scale and walking ability by the Functional Ambulation Classification. Gait speed was assessed by kinemetry. The Kolmogorov-Smirnov test was used to verify data distribution normality. Parametric variables

\footnotetext{
1 Study conducted at the Laboratory for Analysis of Human Movement of the Postgraduate Physical Therapy Program at Universidade Federal do Rio Grande do Norte (PPG-Ft/UFRN), Natal, Brazil.
}

* HMJSB: MCs, e-mail: fsthelobritto@gmail.com. LAM: MCs, e-mail: lumendes_pe@hotmail.com. CCM: MCs, e-mail: cinthiacmoreno@outlook.com. EMGSS: MCs, e-mail: emilia.marciagss@hotmail.com. ARRL:PhD, e-mail: raquellindquist@ufrnet.br. 
were correlated by Pearson's test and their non-parametric parameters by Spearman's test. Functional balance showed a positive correlation with gait speed $(p=0.005 ; r=0.64)$ and walking ability $(p=0.019 ; r=0.56)$. Anteroposterior (AP) and mediolateral (ML) alterations with EO and EC exhibited negative correlations with gait speed (EO: AP amplitude ( $p=0.0049$ and $r=-0.48)$; mean ML deviation ( $p=0.019$ and $r=-0.56) / E C$ : mean AP deviation ( $p=0.018$ and $r=-0.56$ ) and mean ML deviation ( $p=0.032$ and $r=-0.52$ ); AP amplitude $(\mathrm{p}=0.014$ and $\mathrm{r}=-0.57)$ and ML amplitude $(\mathrm{p}=0.032$ and $\mathrm{r}=-0.52)$; postural instability $(\mathrm{p}=0.019$ and $\mathrm{r}=$ $-0.55)$ ) and walking ability (EO: mean AP deviation ( $p=0.05$ and $r=-0.47)$ and AP amplitude $(p=0.024$ and $r=-0.54)$ ). The results suggest correlations between static and functional balance and gait speed and walking ability, and that balance training can be an important component of gait recovery protocols.

Keywords: Balance. Gait. Stroke

\section{Resumo}

Alterações no equilíbrio e marcha são sequelas frequentes em sujeitos com hemiparesia. Este trabalho objetivou verificar se há correlação entre equilíbrio estático e funcional, velocidade e capacidade de deambular. Participaram do estudo 17 sujeitos com hemiparesia crônica, de ambos os sexos (58,8\% de homens) com média de idade de $56,3 \pm 9,73$ anos. A avaliação do equilíbrio estático foi realizada por baropodometria computadorizada em duas condições sensoriais: olhos abertos (AO) e fechados (OF). O equilíbrio funcional foi avaliado pela Escala Equilíbrio de Berg e a capacidade de deambulação, pela Categoria de Deambulação Funcional. A velocidade da marcha foi avaliada por meio da Cinemetria. A normalidade dos dados foi verificada pelo teste de Kolmogorov-Smirnov e as variáveis foram correlacionadas pelos testes de Pearson ou Spearman. $O$ equilíbrio funcional apresentou correlação positiva com a velocidade ( $p=0,005 ; r=0,64)$ e com a capacidade de deambulação $(p=0,019 ; r=0,56)$. As oscilações antero-posteriores (AP) e médio-laterais (ML) com OA e OF apresentaram correlações negativas com velocidade da marcha (OA: amplitude AP ( $p=0,0049$ e $r=-0,48)$; desvio médio $M L(p=0,019$ e $r=-0,56)$ / OF: desvio médio AP ( $p=0,018$ e $r=-0,56)$ e ML ( $p=0,032$ e $r=-0,52)$; amplitude $A P(p=0,014$ e $r=-0,57)$ e $M L$ $(p=0,032$ e $r=-0,52)$; instabilidade postural $(p=0,019$ e $r=-0,55)$ e com capacidade de deambulação (OA: desvio médio AP $(p=0,05$ e $r=-0,47)$ e amplitude AP $(p=0,024$ e $r=-0,54)$. Os resultados sugerem a existência de correlações entre o equilíbrio estático e funcional com a velocidade de marcha e capacidade de deambular, bem como que o treino do equilíbrio pode ser um importante componente para protocolos de recuperação da marcha.

Palavras-chave: Equilíbrio Postural. Marcha. Acidente Vascular Cerebral.

\section{Introduction}

According to the World Health Organization (1), stroke is caused by vascular alterations in the encephalon that lead to hemiparesis and consequent changes in balance, motricity and motor functions.

Balance is a complex process that depends on the integration of visual, vestibular and peripheral nervous systems (2). Moreover, it involves the activation of central commands and neuromuscular responses, particularly muscle strength and reaction time (2). Balance control is required to maintain both static and dynamic posture, such as locomotion. When individuals with hemiparesis are in bipedalism, displacement is generally observed from the center of pressure toward the nonparetic limb in order to maintain balance. In dynamic activities, such as gait, transferring weight from the paretic limb during the stance phase is difficult (3), and changes in space-time variables, including speed, are also observed $(4,5)$.

Studies have shown that improved standing balance control is an important determinant of walking ability during the first year after stroke (6-9), very likely because the use of compensatory strategies while standing, such as transferring weight to the nonparetic limb, is more important for gait recovery than muscle strength in the paretic limb (7-9). However, little is known about the possible correlations between balance, speed and walking ability in the chronic phase of stroke. Thus, the aim of the present study is to determine whether there is a correlation between static and functional balance, gait speed and walking ability in chronic hemiparetic subjects. 


\section{Methods used}

This is a cross-sectional descriptive study (10). The sample was composed of 23 individuals with chronic hemiparesis, recruited by convenience at rehabilitation facilities in Natal, Brazil. The following inclusion criteria were adopted: sequela of hemiparesis caused by a single unilateral ischemic or hemorrhagic stroke; lesion time of more than 6 months; mild spasticity in the paretic limb, according to the Modified Ashworth Scale (11); ability to walk on flat surfaces without orthesis or assistive gait device; and lack of any other neurological or orthopedic impairment that interfered with gait. Six individuals who were unable to perform the entire study protocol were excluded. Thus, the study consisted of 17 chronic hemiparetic individuals. There were no sample losses. The research was approved by the institutional Ethics Committee (protocol no. 266/2008), and all participants gave their informed consent.

\section{Measuring Instruments}

Dynamic functional balance was assessed using the Berg Balance Scale (BBS). The BBS assesses functional balance during common activities of daily living and is considered a suitable and effective assessment of patients with stroke sequelae. Each item consists of a five-point ordinal scale from zero to four points, with a score ranging between 0 and 56 points (12). The ability to perform gait was evaluated by the Functional Ambulation Classification (FAC), a scale validated for populations with neurological disorders that need help from one or more individuals during gait. Scores range from 0 (non-functional walking) to 5 (gait independence) points $(11,13)$.

Static balance was quantified by an Eclipse 3000 computerized baropodometer (Guy-Capron SA, France), a platform with surfaces measuring $40 \mathrm{x}$ $40 \mathrm{~cm}$. This device allowed stabilometric analysis of balance, quantifying oscillations from the center of pressure in the anteroposterior (AP) and mediolateral (ML) direction (14).

Gait speed was obtained by the Qualisys Motion Capture Systems (Qualisys Medical AB, 41113 Gothenburg, Sweden) (15), composed of 3 cameras that captured images at a frequency of $120 \mathrm{~Hz}$. To track gait, passive markers were placed on the calcaneus, lateral malleolus and 5th metatarsal head of the paretic foot (Figure 1).

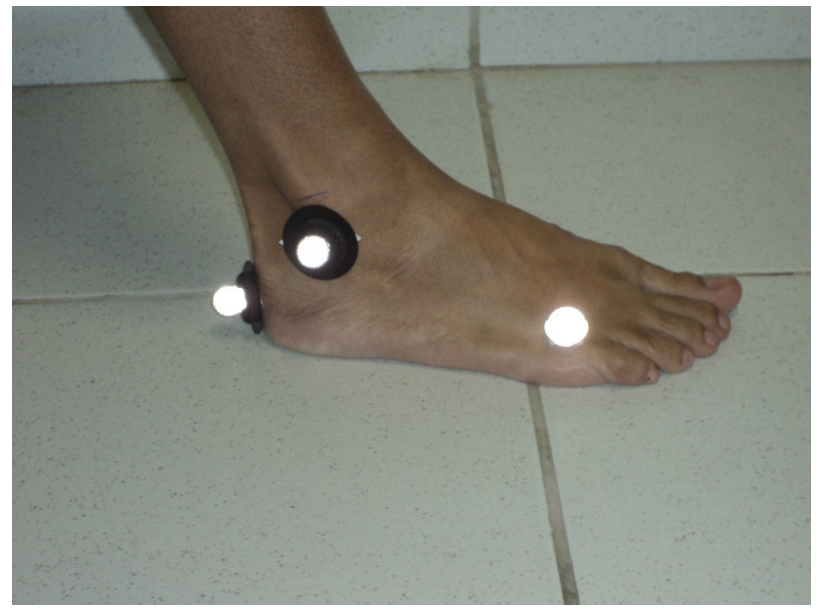

Figure 1 - Assessment of gait speed using markers on the lower paretic limb.

\section{Procedures}

First, the functional balance of subjects was assessed by the 14 BBS items. Walking ability was then evaluated by the FAC.

Static balance was assessed using a baropodometer. The personal data of each volunteer were entered into the software, including name, age, weight and height. Next, participants were positioned barefoot with their feet parallel to each other and their heels $10 \mathrm{~cm}$ apart, arms at their sides and eyes fixed on a point 1 meter away at eye level. Assessments were performed using two different sensory conditions, whose order, selected by random draw, was as follows: bipedal stance with eyes open (EO) and eyes closed (EC). Three 10-second collections were made for each sensory condition, with a 3-minute rest period between conditions. The following variables were analyzed: displacement from the center of pressure in the anteroposterior (DCPap) and mediolateral (DCPml) direction, standard deviation from the center of pressure in the anteroposterior (SDCPap) and mediolateral (SDCPml) direction, as well as postural instability (PI), represented by the area of oscillation from the center of presssure (CoP).

Gait speed was obtained by kinemetry, performed while subjects walked at a comfortable speed over a distance of $8 \mathrm{~m}$ (16-18). A total of 5 repetitions were made and the 5 best cycles were analyzed. Gait cycle speed was analyzed using Visual 3D Basic/RT 3.00.25.8 software (C-Motion, Rockville, MD, USA) (18). To that end, 2 consecutive contacts of the paretic foot with the floor were needed for each attempt. The 
gait speed of each participant was calculated as the mean of 5 gait cycles.

\section{Statistical Analysis}

Statistical analysis was carried out using the SPSS (Statistical Package for the Social Sciences) 16.0 program. The confidence level was set at 5\%. Descriptive statistics (mean and standard deviation) were applied to the clinical, demographic and stabilometric variables. The Kolmogorov-Smirnof test was used to check the variables for normality. Pearson's correlation test was applied to determine the association between static and functional balance and gait speed when the variables exhibited normal distribution, and Spearman's test when they did not.

\section{Results}

The sample was composed of 17 individuals with mean age of $56.3 \pm 9.73$ years, $58.8 \%$ men and $42.2 \%$ women; $58.8 \%$ with right and $42.2 \%$ with left hemiparesis. There was no sample loss. Other clinical and demographic characteristics are depicted in Table 1.

Assessment of static balance showed that higher postural oscillations occurred in the eyes closed condition (Table 2). In the open eyes condition, displacement in the anteroposterior (AP) and mediolateral (ML) direction were similar, albeit with less homogeneity in the ML direction (higher mean absolute deviations). In the EC condition, there was greater oscillation in the ML direction.

Table 1- Clinical and demographic characteristics of subjects

\begin{tabular}{lc}
\hline & Mean \pm SDS \\
\hline Age (years) & $56.3 \pm 9.73$ \\
Lesion time (months) & $31.81 \pm 21.40$ \\
Speed (m/s) & $0.54 \pm 0.26$ \\
FAC & $4.4 \pm 0.7$ \\
BBS & $47.12 \pm 8.34$ \\
Weight & $71.23 \pm 10.67$ \\
Height & $1.60 \pm 0.09$ \\
\hline
\end{tabular}

Note: Abbreviations: FAC: Functional Ambulation Classification; BBS: Berg Balance Scale.
Table 2 - Means ( \pm standard deviation) of stabilometric variables

\begin{tabular}{lcc}
\hline & $\begin{array}{c}\text { Eyes Open } \\
\text { Condition }\end{array}$ & $\begin{array}{c}\text { Eyes Closed } \\
\text { Condition }\end{array}$ \\
\hline DCPap $(\mathrm{mm})$ & $3.89 \pm 1.85$ & $6.17 \pm 5.79$ \\
MDCPap $(\mathrm{mm})$ & $0.91 \pm 0.48$ & $1.31 \pm 0.88$ \\
$\mathrm{DCPml}(\mathrm{mm})$ & $3.57 \pm 1.57$ & $7.31 \pm 13.34$ \\
$\mathrm{MDCPml}(\mathrm{mm})$ & $2.69 \pm 8.14$ & $1.17 \pm 1.49$ \\
$\mathrm{AOC}\left(\mathrm{mm}^{2}\right)$ & $10.67 \pm 6.26$ & $20.70 \pm 30.25$ \\
\hline
\end{tabular}

Note: Abbreviations: DCPap: displacement from the center of pressure in the anteroposterior direction; MDCPap: mean deviation from the center of pressure in the anteroposterior direction; DCPml: displacement from the center of presssure in the mediolateral direction; MDCPml: mean deviation from the center of pressure in the mediolateral direction; $\mathrm{AOC}$ : area of oscillation from the center of pressure.

Moderate negative correlations were observed between the FAC and static balance and between speed and static balance (Table 3). These results indicate that the greater the postural instability, the lower the walking ability and gait speed. In the eyes closed condition, walking ability correlated only with displacement from the center of pressure in the AP direction, while gait speed correlated with displacement from the center of pressure in the AP direction and standard deviation from the center of pressure in the ML direction. In the eyes closed condition, static balance variables correlated only with gait speed (Table 3).

Table 3 - Static stabilometric variables: correlation with walking ability (FAC) and gait speed

(To de continued)

\begin{tabular}{|c|c|c|c|c|c|}
\hline & \multicolumn{3}{|c|}{ FAC } & \multicolumn{2}{|c|}{ Gait speed } \\
\hline \multirow{6}{*}{ EO } & & $p$ & $r$ & $p$ & $r$ \\
\hline & DCPap & 0.02 * & -0.54 & $0.05^{*}$ & -0.48 \\
\hline & MDCРap & $0.05^{*}$ & -0.47 & 0.07 & -0.44 \\
\hline & DCPml & 0.60 & -0.13 & 0.42 & -0.21 \\
\hline & MDCPml & 0.10 & -0.40 & 0.02 * & -0.56 \\
\hline & Area & 0.26 & -0.29 & 0.21 & -0.32 \\
\hline
\end{tabular}


Table 3 - Static stabilometric variables: correlation with walking ability (FAC) and gait speed

(Conclusion)

\begin{tabular}{cccccc} 
& \multicolumn{3}{c}{ FAC } & \multicolumn{3}{c}{ Gait speed } \\
\hline & DCPap & 0.11 & -0.39 & $0.01^{*}$ & -0.57 \\
& MDCPap & 0.11 & -0.39 & $0.02^{*}$ & -0.56 \\
EC & DCPml & 0.46 & -0.19 & $0.03^{*}$ & -0.52 \\
& MDCPml & 0.45 & -0.19 & $0.03^{*}$ & -0.52 \\
& OCP & 0.23 & -0.30 & $0.02^{*}$ & -0.56 \\
\hline
\end{tabular}

Note: Abbreviations: EO: eyes open condition; EC, eyes closed condition; DCPap: displacement from the center of pressure in the anteroposterior direction; MDap: mean deviation from the center of pressure in the anteroposterior direction; DCPml: displacement from the center of pressure in the mediolateral direction; MDml, mean deviation from the center of pressure in the mediolateral direction; OCP, oscillation from the center of pressure. Significant comparisons * $(p \leq 0.05)$.

Dynamic balance correlated with both gait speed $(\mathrm{p}=0.005 ; \mathrm{r}=0.64)$ and FAC $(\mathrm{p}=0.019 ; \mathrm{r}=0.56)$, indicating that the better the functional balance, the greater the speed and walking ability (Figure 2).

\section{Discussion}

The present study showed that patients with chronic hemiparesis after stroke exhibited greater stabilometric oscillations with eyes closed, and negative correlations between stablelometry and the FAC, as well as between stabilometry and gait speed. Furthermore positive correlations were observed between the BBS and the FAC and between BBS and gait speed. These findings may be related to sample characteristics, given that individuals displayed good functional balance (12), needed little or no help in walking $(11,13)$, walked at moderate speed $(20,21)$, and showed greater static balance oscillation in bipedalism $(22,23)$ when compared to a healthy population.

Analysis of stabilometry indicated that more CoP movement occurred in the ML direction in hemiparetic individuals, both with eyes open and closed. This finding is likely related to the fact that the CoP in these individuals was displaced toward the nonparetic limb. This may have occurred in an attempt at maintaining standing balance.
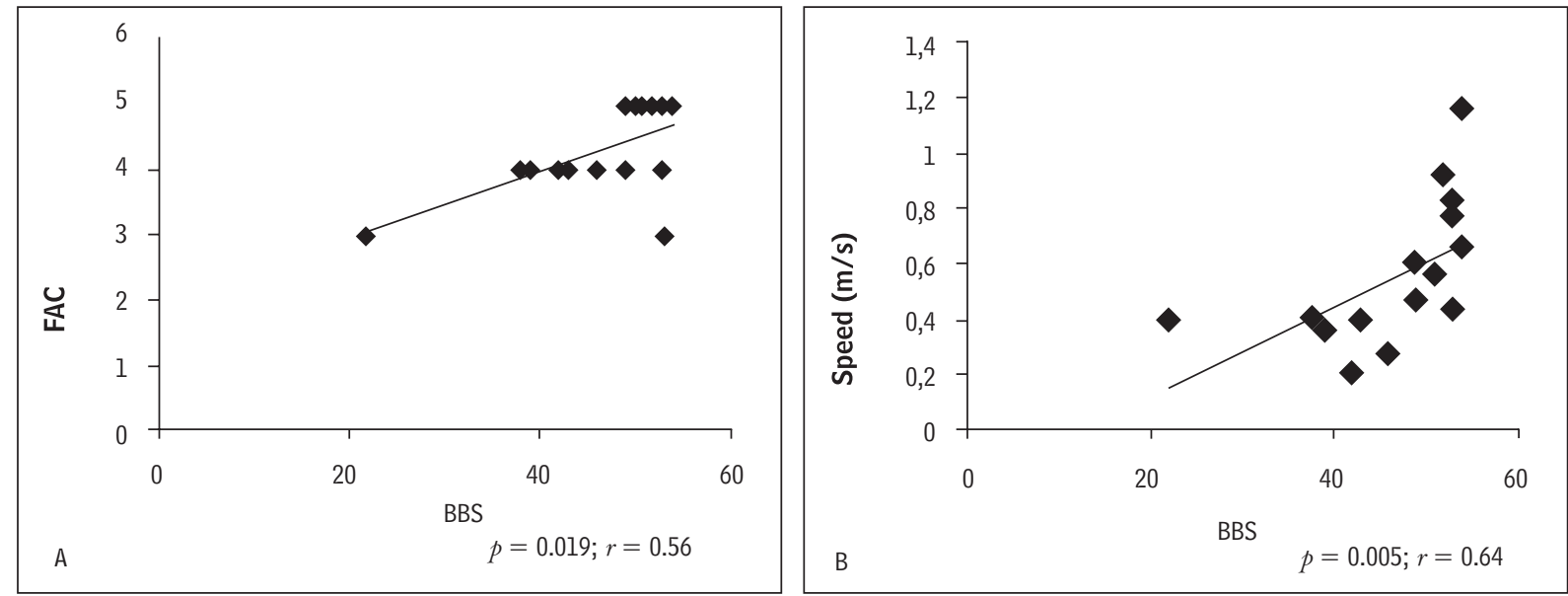

Figure 2 - Significant correlations between functional and static balance (BBS), walking ability (FAC) and gait speed. A: BBS X FAC. B: BBS X Speed

The data also show greater instability with eyes closed than open, suggesting that individuals in this sample may have more difficulty in adopting compensatory strategies to maintain the orthostatic position, due to the absence of visual input (24). It is known that balance is influenced by proprioceptive, visual and vestibular systems. Since hemiparetic individuals often exhibit impaired proprioception, visual information is an important tool for correcting proprioceptive deficits (25).

This study found a negative correlation between both stabilometric data and speed and between stabilometry and the FAC, suggesting that the less the movement in the AP and ML directions, the greater the speed and walking ability of individuals. 
Other studies $(22,23)$ also found that an increase in mediolateral oscillation in the standing position may indicate lower gait. Standing balance disorders may lead to compromised coordination and symmetry in paretic and nonparetic limbs (22), resulting in slower walking speed.

For people with hemiparesis to resume walking after stroke, standing balance must be controlled $(23,6)$. Our results demonstrate that the greater the standing stability, the better the walking ability. This can be explained by compensatory strategies while standing, such as transferring weight to the nonparetic side (6), and regulating paretic hemibody oscillation by means of mechanisms generated by the nonparetic ankle (26).

Another interesting result was the positive correlation between gait speed and functional balance, corroborating other studies $(27,28)$. This finding may be related to the fact that the BBS observes a number of dynamic activities, where movement away from the center of body mass is promoted, as occurs during gait (12). This can also be explained by the fact that functional walking ability depends on controlling balance and gait speed, among other factors (29).

The correlation between the FAC and BBS was also positive, suggesting that the better the functional balance the lower the dependence on other individuals to perform gait. The relationship between functional balance and controlled locomotion has been documented in patients with hemiparesis (29). These individuals learn compensatory strategies to control their balance (30), thereby adapting to the conditions caused by the lesion in order to perform functional activities, such as independent gait.

The main limitation of this study was sample size, since it consisted of only 17 hemiparetic individuals. For a better understanding of neurological and physiological factors that involve the balance and gait of patients with chronic post-stroke hemiparesis, it is suggested that new studies be conducted associating other important variables, such as motor impairment, lesion site, electromyography and paretic and nonparetic limbs.

\section{Final Considerations}

The findings of this investigation indicate correlations between both static and functional balance and gait speed and walking ability. In light of chronic alterations in motricity resulting from brain lesion, such as impaired strength and hypertonia, good balance may be essential in reestablishing gait. Thus, it is suggested that balance training may be an important component for gait recovery protocols.

This study received no financial support.

\section{References}

1. Stroke, Cerebrovascular accident. World Health Organization. [Cited in: Aug 21, 2011]. Available from: http:// www.who.int/topics/cerebrovascularaccident/en.

2. 2. Overstall PW. The use of balance training in elderly people with falls. Clinical Geron. 2003;13(2):153-61.

3. Bensoussan L, Viton JM, Barotsis N, Delarque A. Evaluation of patients with gait abnormalities in physical and rehabilitation medicine settings. J Rehabil Med. 2008;40:497-507.

4. Perry J. Análise da Marcha: Marcha Patológica. Barueri-SP: Manole; 2005. v.2.

5. Hsu AL, Tang PF, Jan MH. Analysis of impairments influencing gait velocity and asymmetry of hemiplegic patients after mild to moderate stroke. Arch Phys Med Rehabil. 2003;84:1185-93.

6. Kollen B, Van de Port I, Lindeman E, Twisk J, Kwakkel G. Predicting Improvement in Gait After StrokePredicting Improvement in Gait After Stroke: A Longitudinal Prospective Study. Stroke. 2005;36:2676-80.

7. De Haart M, Geurts AC, Huidekoper SC, Fasotti L, van Limbeek J. Recovery of standing balance in postacute stroke patients: a rehabilitation cohort study. Arch Phys Med Rehabil. 2004;85:886-95.

8. Dettmann MA, Londer MT, Sepic SB. Relationships among walking performance, postural stability, and functional assessments of the hemiplegic patient. Am J Phys Med. 1987;66:77-90.

9. Garland SJ, Willems DA, Ivanova TD, Miller KJ. Recovery of standing balance and functional mobility after stroke. Arch Phys Med Rehabil. 2003;84:1753-59.

10. Pereira MG. Epidemiologia: Teoria e prática. Rio de Janeiro: Guanabara Koogan, 1995.

11. Wade DT. Measurement in neurological rehabilitation. New York, NY: Oxford University Press; 1992. 
12. Blum L, Korner-Bitensky N. Usefulness of the Berg Balance Scale in Stroke Rehabilitation: A Systematic Review. Phys Ther 2008;88(5):559-66.

13. Holden MK, Gill KM, Magliozzi MR, Nathan J, PiehlBaker L. Clinical gait assessment in the neurologically impaired. Phys Ther. 1984;64:35-40.

14. Bankoff AD, Bekedorf RG, Schmidt A, Ciol P, Zamai CA. Análise do equilíbrio corporal estático através de um baropodômetro eletrônico. Revista Conexões. 2006;4(2):19-30.

15. Qualisys Track Manager User Manual. Qualisys AB. Suécia, 2006.

16. Harris-Love ML, Macko RF, Whitall J, Forrester LW. Improved hemiparetic muscle activation in treadmill versus overground walking. Neurorehabil Neural Repair. 2004;18:154-60.

17. Matsas A, Taylor NF, McBurney H. Knee joint kinematics from familiarized treadmill walking can be generalized to overground walking in young unimpaired subjects. Gait Posture. 2000;11:46-53.

18. Wass E, Taylor NF, Matsas A. Familiarization to treadmill walking in unimpaired older people. Gait Posture. 2005;21:72-9.

19. Visual3D Online Documentation. C-Motion, Inc. [Cited in jan 15, 2009]. Available From: http://www.c-motion.com/help.

20. Olney SJ, Richards C. Hemiparetic gait following stroke. Part I: Characteristics. Gait and Poslure. 1996;4(2):136-48.

21. Shumway-Cook A, Woollacoot MH. Controle Muscular: Teoria e aplicações práticas. Barueri-SP: Manole; 2003.

22. Titianova EB, Tarkka IM. Asymmetry in walking performance and postural sway in patients with chronic unilateral cerebral infarction. J Rehabil Res Dev 1995;32:236-44.
23. Boza R, Duarte E, Belmonte R, Marco E, Muniesa JM, Tejero M, Sebastiá E, Escalada YF. Estudio baropodométrico en el hemipléjico vascular: relación con la discapacidad, equilibrio y capacidad de marcha. Rehabilitación 2007;41(1):3-9.

24. Prokop T, Schubert M, Berger W. Visual influence on human locomotion. Modulation to changes in optic flow. Exp. Brain Res 1997;114:63-70.

25. Di Fabio RP, Badke MB. Relationship of Sensory Organization to Balance Function in Patients with Hemiplegia. Physical Therapy Volume 1990;70(9):542-8.

26. Geurtsa ACH, Haarta M, van Nessa IJW, Duysensa $\mathrm{J}$. A review of standing balance recovery from stroke. Gait \& Posture 22 (2005) 267-81.

27. Richards CL, Malouin F, Dumas F, Tardif D. Gait velocity as an outcome measure of locomotor recovery after stroke. In: Craik R, Oatis CA. Gait Analysis: Theory and Applications. St Louis: Mosby; 1995:355-64.

28. Van de Port IG, Kwakkel G, Lindeman E. Community Ambulation in Patients with Chronic Stroke: How is it Related to Gait Speed? J Rehabil Med. 2008;40:23-7.

29. Bohannon RW. Standing balance, lower extremity muscle strength, and walking performance of patients referred for physical therapy. Percept Motor Skills 1995. 80;379-85.

30. Juneja G, Czyrny JJ, Linn RT. Admission balance and outcomes of patients admitted for acute inpatient rehabilitation. Am J Phys Med Rehabil. 1998;77:388-93.

Recebido: 24/04/2012

Received: 04/24/2012

Aprovado: 26/06/2015 Approved: 06/26/2015 
